\title{
Product-specific COVID-19 vaccine effectiveness against secondary infection in close contacts, Navarre, Spain, April to August 2021
}

\author{
Iván Martínez-Baz ${ }^{1,2,3}$, Camino Trobajo-Sanmartín ${ }^{3,4}$, Ana Miqueleiz ${ }^{3,4}$, Marcela Guevara ${ }^{1,2,3}$, Miguel Fernández-Huerta ${ }^{3,4}$, \\ Cristina Burgui ${ }^{1,2,3}$, Itziar Casado ${ }^{1,2,3}$, María Eugenia Portillo ${ }^{3,4}$, Ana Navascués ${ }^{3,4}$, Carmen Ezpeleta ${ }^{3,4}$, Jesús Castilla ${ }^{1,2,3}$, the \\ Working Group for the Study of COVID-19 in Navarre 5 \\ 1. Instituto de Salud Pública de Navarra, Pamplona, Spain \\ 2. CIBER Epidemiología y Salud Pública (CIBERESP), Spain \\ 3. Navarra Institute for Health Research (IdiSNA), Pamplona, Spain \\ 4. Clinical Microbiology Department, Complejo Hospitalario de Navarra, Pamplona, Spain \\ 5. Other members of the Working Group for the Study of COVID-19 in Navarre are listed in the Investigators tab
}

Correspondence: Jesús Castilla (jcastilc@navarra.es)

Investigators: the Investigators are listed at the end of the article.

Citation style for this article:

Martínez-Baz Iván, Trobajo-Sanmartín Camino, Miqueleiz Ana, Guevara Marcela, Fernández-Huerta Miguel, Burgui Cristina, Casado Itziar, Portillo María Eugenia, Navascués Ana, Ezpeleta Carmen, Castilla Jesús, the Working Group for the Study of COVID-19 in Navarre. Product-specific CoVID-19 vaccine effectiveness

against secondary infection in close contacts, Navarre, Spain, April to August 2021. Euro Surveill. 2021;26(39): pii=2100894. https://doi.org/10.2807/1560-7917.

ES.2021.26.39.2100894

COVID-19 vaccine effectiveness by product (two doses Comirnaty, Spikevax or Vaxzevria and one of Janssen), against infection ranged from $50 \%(95 \% \mathrm{Cl}: 42$ to 57$)$ for Janssen to $86 \%$ (70 to 93 ) for Vaxzevria-Comirnaty combination; among $\geq 60$ year-olds, from $17 \%(-26$ to 45) for Janssen to $68 \%$ (48 to 80 ) for Spikevax; and against hospitalisation from $74 \%$ (43 to 88 ) for Janssen to $>90 \%$ for other products. Two doses of vaccine were highly effective against hospitalisation, but suboptimal for infection control.

Up to April 2021, four coronavirus disease (COVID19) vaccines had been authorised by the European Medicines Agency to prevent severe acute respiratory syndrome coronavirus 2 (SARS-CoV-2) infections and to reduce the impact of this pandemic on hospital admissions and mortality. Comirnaty (BNT162 b2 mRNA, BioNTech-Pfizer, Mainz, Germany/New York, United States (US)) and Spikevax (mRNA-1273, Moderna, Cambridge, US) are based on mRNA, while Vaxzevria (ChAdOx1 nCoV-19, Oxford-AstraZeneca, Cambridge, United Kingdom) and Janssen vaccine (Ad26.COV2-S, Janssen-Cilag International NV, Beerse, Belgium) are adenovirus-based vector vaccines [1-4]. Two doses are needed for full vaccination for all vaccines except Janssen, which only requires one dose.

We aimed to assess the product-specific COVID-19 vaccine effectiveness (VE) in preventing infection and hospitalisation in a prospective dynamic cohort of adults ( $\geq 18$ years old) who were close contacts of COVID-19 cases from April to August 2021 in Navarre, Spain. We compared products in population groups that were vaccinated indistinctly with various products.

\section{Identification of close contacts and information sources}

In Spain, to control COVID-19 transmission, all laboratory-confirmed COVID-19 cases are interviewed to detect their close contacts [5]. Close contacts are defined as any person who either had high-risk exposure to a confirmed COVID-19 case within a timeframe ranging from 2 days before the onset of symptoms in the case to 10 days after the onset of symptoms, or, for asymptomatic cases, in the 2 days before the sample which led to confirmation was taken, to 10 days after the sample was taken [6]. Close contacts are encouraged to be tested immediately and 7 to 10 days after the last exposure by RT-PCR. In symptomatic contacts, a positive antigen test within 5 days from the symptom onset is also considered a confirmed infection [7].

In our study, we excluded close contacts with a prior positive test, nursing home residents and those who did not complete the testing protocol. Age, sex, chronic conditions and contact setting were obtained from the enhanced epidemiological surveillance of COVID-19 [5]. Additional information about methods is described in the Supplementary Material.

\section{Vaccine products administered}

In Spain, the COVID-19 vaccination campaign targeted adults starting with older age groups and gradually moving towards younger ones [8]. Although the product administered mainly depended on the availability at the particular moment, people aged $\geq 70$ years were mainly vaccinated with Comirnaty or Spikevax, and those aged 60-69 years were mainly vaccinated with Vaxzevria. All products were used in people from 18 to 59 years of age; however, those who received the 
TABLE 1

COVID-19 outcomes by characteristics of close contacts and vaccination status of their index cases, dynamic cohort ${ }^{\mathrm{a}}$, Navarre, Spain, April-August $2021(\mathrm{n}=30,240)$

\begin{tabular}{|c|c|c|c|c|c|c|c|}
\hline \multirow[t]{2}{*}{ Characteristics } & \multirow[t]{2}{*}{ Total } & \multicolumn{2}{|c|}{ All SARS-CoV-2 infections ${ }^{b}$} & \multicolumn{2}{|c|}{$\begin{array}{c}\text { Symptomatic } \\
\text { SARS-CoV-2 infections }\end{array}$} & \multicolumn{2}{|c|}{ COVID-19 hospital admission } \\
\hline & & Number & $\begin{array}{c}\text { Secondary attack } \\
\text { rate, \% }\end{array}$ & Number & $\begin{array}{c}\text { Secondary attack } \\
\text { rate, \% }\end{array}$ & Number & $\begin{array}{c}\text { Secondary attack } \\
\text { rate, \% }\end{array}$ \\
\hline Total & 30,240 & 7,177 & 24 & 4,676 & 16 & 263 & 0.9 \\
\hline \multicolumn{8}{|l|}{ Age groups (years) } \\
\hline $18-34$ & 9,608 & 2,929 & 31 & 1,839 & 19 & 21 & 0.2 \\
\hline $35-49$ & 7,655 & 1,810 & 24 & 1,278 & 17 & 60 & 0.8 \\
\hline $50-69$ & 10,286 & 1,893 & 18 & 1,220 & 12 & 119 & 1.2 \\
\hline$\geq 70$ & 2,691 & 545 & 20 & 339 & 13 & 63 & 2.3 \\
\hline \multicolumn{8}{|l|}{ Sex } \\
\hline Male & 14,590 & 3,553 & 24 & 2,182 & 15 & 138 & 0.9 \\
\hline Female & 15,650 & 3,624 & 23 & 2,494 & 16 & 125 & 0.8 \\
\hline \multicolumn{8}{|c|}{ Major chronic conditions } \\
\hline No & 21,706 & 5,214 & 24 & 3,413 & 16 & 137 & 0.6 \\
\hline Yes & 8,534 & 1,963 & 23 & 1,263 & 15 & 126 & 1.5 \\
\hline \multicolumn{8}{|c|}{ Vaccination status of close contacts } \\
\hline Unvaccinated & 14,348 & 4,811 & 34 & 3,278 & 23 & 216 & 1.5 \\
\hline Partially vaccinated $^{c}$ & 4,138 & 723 & 18 & 405 & 10 & 16 & 0.4 \\
\hline Fully vaccinated ${ }^{c}$ & 11,754 & 1,643 & 14 & 993 & 8 & 31 & 0.3 \\
\hline \multicolumn{8}{|l|}{ Contact setting } \\
\hline Household & 16,305 & 4,639 & 29 & 3,096 & 19 & 212 & 1.3 \\
\hline Other & 13,935 & 2,538 & 18 & 1,580 & 11 & 51 & 0.4 \\
\hline \multicolumn{8}{|c|}{ Month of contact (2021) } \\
\hline April & 7,137 & 2,143 & 30 & 1,550 & 22 & 155 & 2.2 \\
\hline May & 2,988 & 722 & 24 & 527 & 18 & 35 & 1.2 \\
\hline June & 2,077 & 457 & 22 & 332 & 16 & 7 & 0.3 \\
\hline July & 13,138 & 2,817 & 21 & 1,531 & 12 & 38 & 0.3 \\
\hline August & 4,900 & 1,038 & 21 & 736 & 15 & 28 & 0.6 \\
\hline \multicolumn{8}{|c|}{ Vaccination status of index case } \\
\hline Unvaccinated & 25,024 & 6,237 & 25 & 4,078 & 16 & 236 & 0.9 \\
\hline Partially vaccinated ${ }^{c}$ & 1,729 & 328 & 19 & 202 & 12 & 12 & 0.7 \\
\hline Fully vaccinated ${ }^{\mathrm{c}}$ & 3,487 & 612 & 18 & 396 & 11 & 15 & 0.4 \\
\hline
\end{tabular}

COVID-19: coronavirus disease; SARS-CoV-2: severe acute respiratory syndrome coronavirus 2.

${ }^{a}$ Close contacts with a prior positive test, nursing home residents and those who did not complete the testing protocol were excluded.

${ }^{\mathrm{b}}$ All infections included asymptomatic and symptomatic SARS-CoV-2 infections.

'A person was considered fully vaccinated $\geq 14$ days after receiving one dose of Janssen or the second dose of other vaccines, and partially vaccinated $\geq 14$ days after receiving only the first dose of Spikevax, Comirnaty or Vaxzevria.

first dose of Vaxzevria could choose the second dose between Vaxzevria or Comirnaty. With this exception, all people received the same product for the second dose.

Information about COVID-19 vaccine doses, product and date of administration were obtained from the regional vaccination register. We considered a person fully vaccinated $\geq 14$ days after receiving one dose of Janssen or the second dose of other vaccines, and partially vaccinated $\geq 14$ days after receiving only the first dose of Spikevax, Comirnaty or Vaxzevria.

\section{Statistical analysis of product-specific vaccine effectiveness}

We compared the incidence of SARS-CoV-2 infection, of symptomatic cases and of COVID-19 hospitalisation by product-specific COVID-19 vaccination status as a variable with nine categories, with unvaccinated people as reference category. The same risk period was assigned to everyone in the cohort; therefore, the Cox regression provided estimates of the crude and adjusted relative risks (RR) with 95\% confidence intervals (CI). Adjusted models included age groups, sex, chronic conditions, contact setting, month and COVID-19 vaccination status of the index case. 
TABLE 2

Product-specific COVID-19 vaccine effectiveness, dynamic cohort, Navarre, Spain, April-August 2021 ( $\mathrm{n=30,240)}$

\begin{tabular}{|c|c|c|c|c|}
\hline $\begin{array}{l}\text { COVID-19 outcome evaluated and vaccination } \\
\text { status }\end{array}$ & Cases / total & Secondary attack rate, \% & $\begin{array}{l}\text { Crude VE } \\
(95 \% \mathrm{Cl})\end{array}$ & $\begin{array}{c}\text { Adjusted } \\
\text { VE }(95 \% \mathrm{Cl})^{\mathrm{b}}\end{array}$ \\
\hline \multicolumn{5}{|l|}{ All SARS-CoV-2 infections ${ }^{a}$} \\
\hline Unvaccinated & $4,811 / 14,348$ & 34 & Reference & Reference \\
\hline 1 dose of Janssen & $209 / 997$ & 21 & $37(28$ to 46$)$ & $50(42$ to 57$)$ \\
\hline 1 dose of Spikevax & $70 / 517$ & 14 & 60 (49 to 68$)$ & 66 (56 to 73$)$ \\
\hline 2 doses of Spikevax & $85 / 1,127$ & 8 & $77(72$ to 82$)$ & 82 (78 to 86$)$ \\
\hline 1 dose of Comirnaty & $351 / 2,022$ & 17 & $48(42$ to 53$)$ & $57(52$ to 61$)$ \\
\hline 2 doses of Comirnaty & $1,070 / 7,972$ & 13 & 60 (57 to 62) & 69 (66 to 72$)$ \\
\hline 1 dose of Vaxzevria & $302 / 1,599$ & 19 & 44 (37 to 50$)$ & 41 (34 to 48$)$ \\
\hline 2 doses of Vaxzevria & $272 / 1,539$ & 18 & $47(40$ to 53$)$ & $54(48$ to 60$)$ \\
\hline 1 dose of Vaxzevria +1 dose of Comirnaty & $7 / 119$ & 6 & 82 (63 to 92$)$ & 86 (70 to 93) \\
\hline \multicolumn{5}{|l|}{ Symptomatic SARS-CoV-2 infection } \\
\hline Unvaccinated & $3,278 / 14,348$ & 23 & Reference & Reference \\
\hline 1 dose of Janssen & $126 / 997$ & 13 & $45(34$ to 54$)$ & $54(45$ to 62$)$ \\
\hline 1 dose of Spikevax & $38 / 517$ & 7 & $68(56$ to 77$)$ & 71 (61 to 79$)$ \\
\hline 2 doses of Spikevax & $46 / 1,127$ & 4 & $82(76$ to 87$)$ & $85(80$ to 89$)$ \\
\hline 1 dose of Comirnaty & $182 / 2,022$ & 9 & $61(54$ to 66$)$ & $66(60$ to 71$)$ \\
\hline 2 doses of Comirnaty & $645 / 7,972$ & 8 & $65(61$ to 67$)$ & $72(69$ to 75$)$ \\
\hline 1 dose of Vaxzevria & $185 / 1,599$ & 12 & $49(41$ to 56$)$ & 46 (37 to 54$)$ \\
\hline 2 doses of Vaxzevria & $173 / 1,539$ & 11 & $51(43$ to 58$)$ & $56(48$ to 63$)$ \\
\hline 1 dose of Vaxzevria +1 dose of Comirnaty & $3 / 119$ & 3 & 89 (66 to 96$)$ & 91 (71 to 97 ) \\
\hline \multicolumn{5}{|l|}{ COVID-19 hospital admission } \\
\hline Unvaccinated & $216 / 14,348$ & 1.5 & Reference & Reference \\
\hline 1 dose of Janssen & $8 / 997$ & 0.8 & $47(-8$ to 74$)$ & 74 (43 to 88$)$ \\
\hline 1 dose of Spikevax & $2 / 517$ & 0.4 & $74(-3$ to 94$)$ & $73(-10$ to 93$)$ \\
\hline 2 doses of Spikevax & $1 / 1,127$ & 0.1 & $96(58$ to 99$)$ & $98(82$ to 100$)$ \\
\hline 1 dose of Comirnaty & $6 / 2,022$ & 0.3 & 80 (56 to 92$)$ & $86(69$ to 94$)$ \\
\hline 2 doses of Comirnaty & $20 / 7,972$ & 0.3 & 83 (74 to 89 ) & 93 (88 to 96$)$ \\
\hline 1 dose of Vaxzevria & $8 / 1,599$ & 0.5 & $67(33$ to 84$)$ & 78 (54 to 89$)$ \\
\hline 2 doses of Vaxzevria & $2 / 1,539$ & 0.1 & $91(65$ to 98$)$ & 95 (79 to 99) \\
\hline 1 dose of Vaxzevria +1 dose of Comirnaty & $0 / 119$ & 0 & $100(\mathrm{NA})$ & $100(N A)$ \\
\hline
\end{tabular}

$\mathrm{Cl}$ : confidence interval; COVID-19: coronavirus disease; NA: not applicable; SARS-CoV-2: severe acute respiratory syndrome coronavirus 2; VE: vaccine effectiveness.

a Cases included asymptomatic and symptomatic SARS-CoV-2 infections.

${ }^{b}$ VE adjusted by age group (18-34, 35-49, 50-69 and $\geq 70$ years), sex, major chronic conditions, contact setting (household or other), month and vaccination status of index case.

These analyses estimate the VE by product, but product comparison may not be valid.

The VE was estimated as a percentage: (1-adjusted RR) $x$ 100. Product-specific effectiveness was estimated in close contacts by age group (18-59 and $\geq 60$ years), contact setting (household or other), vaccination status of the index case and by SARS-CoV-2 variant (Phylogenetic Assignment of Named Global Outbreak (Pango) lineage designation B.1.1.7 (Alpha), B.1.617.2 (Delta) and other). For each product and number of doses, infection incidence $\geq 90$ days after the last dose was compared to infection incidence within 90 days after the last dose. As individuals aged 18-59 years could have been vaccinated with all products, the relative VE in this age group was used to compare vaccine products in an analysis limited to 90 days from the last dose to reduce product differences in time since the last dose.

\section{Estimates of product-specific vaccine effectiveness}

The study cohort included 30,240 close contacts of 12,263 index cases. In the cohort of close contacts, 7,177 (23.7\%) SARS-CoV-2 infections were confirmed and $263(3.7 \%)$ of them led to hospitalisation. Characteristics of the study population by outcomes and product-specific vaccination status are shown in Table 1 and Supplementary Tables S1 and S2.

The adjusted point VE estimate against COVID-19 hospitalisation was higher than $90 \%$ for two vaccine doses 
Product-specific COVID-19 vaccine effectiveness against SARS-CoV-2 infection by age group, dynamic cohort, Navarre, Spain, April-August $2021(\mathrm{n}=30,240)$

\begin{tabular}{|c|c|c|c|c|}
\hline Study population and vaccination status & Cases/total & Secondary attack rate, \% & $\begin{array}{l}\text { Crude VE } \\
(95 \% \mathrm{Cl})\end{array}$ & $\begin{array}{c}\text { Adjusted } \\
\text { VE }(95 \% \mathrm{Cl})^{\mathrm{a}}\end{array}$ \\
\hline \multicolumn{5}{|l|}{ Close contacts $18-59$ years old } \\
\hline Unvaccinated & $4,386 / 13,114$ & 33 & Reference & Reference \\
\hline 1 dose of Janssen & $180 / 892$ & 20 & $40(30$ to 48$)$ & $52(44$ to 59$)$ \\
\hline 1 dose of Spikevax & $63 / 489$ & 13 & $61(51$ to 70$)$ & $68(58$ to 75$)$ \\
\hline 2 doses of Spikevax & $65 / 912$ & 7 & 79 (73 to 83$)$ & 83 (78 to 86$)$ \\
\hline 1 dose of Comirnaty & $291 / 1,738$ & 17 & $50(44$ to 55$)$ & $60(54$ to 64$)$ \\
\hline 2 doses of Comirnaty & $743 / 5,863$ & 13 & $62(59$ to 65$)$ & $70(67$ to 73$)$ \\
\hline 1 dose of Vaxzevria & $100 / 588$ & 17 & $49(38$ to 58$)$ & $45(33$ to 55$)$ \\
\hline 2 doses of Vaxzevria & $148 / 808$ & 18 & $45(35$ to 53$)$ & $54(46$ to 61$)$ \\
\hline 1 dose of Vaxzevria +1 dose of Comirnaty & $7 / 119$ & 6 & 82 (63 to 92$)$ & 86 (70 to 93$)$ \\
\hline \multicolumn{5}{|l|}{ Close contacts $\geq 60$ years old } \\
\hline Unvaccinated & $425 / 1,234$ & 34 & Reference & Reference \\
\hline 1 dose of Janssen & $29 / 105$ & 28 & $20(-17$ to 45$)$ & $17(-26$ to 45$)$ \\
\hline 1 dose of Spikevax & $7 / 28$ & 25 & $27(-53$ to 66$)$ & $25(-59$ to 65$)$ \\
\hline 2 doses of Spikevax & $20 / 215$ & 9 & $73(58$ to 83$)$ & 68 (48 to 80$)$ \\
\hline 1 dose of Comirnaty & $60 / 284$ & 21 & $39(20$ to 53$)$ & $32(8$ to 49$)$ \\
\hline 2 doses of Comirnaty & $327 / 2,109$ & 16 & 55 (48 to 61$)$ & $50(37$ to 60$)$ \\
\hline 1 dose of Vaxzevria & $202 / 1,011$ & 20 & $42(31$ to 51$)$ & 24 (3 to 40$)$ \\
\hline 2 doses of Vaxzevria & $124 / 731$ & 17 & $51(40$ to 60$)$ & $44(25$ to 57$)$ \\
\hline
\end{tabular}

$\mathrm{Cl}$ : confidence interval; COVID-19: coronavirus disease; SARS-CoV-2: severe acute respiratory syndrome coronavirus 2; VE: vaccine effectiveness.

a VE adjusted by age group (18-34, 35-49, 50-69 and $\geq 70$ years), sex, major chronic conditions, contact setting (household or other), month and vaccination status of index case.

These analyses estimate the VE by product, but product comparison may not be valid.

of any product, and was $74 \%(95 \% \mathrm{Cl}: 43$ to 88$)$ for one dose of Janssen. Effectiveness of full vaccination in preventing SARS-CoV-2 infection ranged from $50 \%$ ( $95 \% \mathrm{Cl}: 42$ to 57 ) for Janssen to $86 \%$ (95\% Cl: 70 to 93 ) for the Vaxzevria-Comirnaty combination. The VE of full vaccination with two doses was $82 \%$ (95\% Cl: 78 to 86 ) for Spikevax, $69 \%$ ( $95 \% \mathrm{Cl}: 66$ to 72 ) for Comirnaty and $54 \%$ (95\% Cl: 48 to 60) for Vaxzevria. The VE estimates were similar or higher against symptomatic infection (Table 2).

The effectiveness of full vaccination in preventing SARS-CoV-2 infection was higher in people aged 18-59 years than in those aged $\geq 60$ years for all vaccine products. Among people aged $\geq 60$ years, full vaccination estimates ranged from $17 \%(95 \% \mathrm{Cl}:-26$ to 45$)$ for Janssen to $68 \%$ (95\% Cl: 48 to 80 ) for Spikevax (Table 3).

The VE estimates did not change substantially when close contacts of vaccinated index cases were excluded or only household contacts were considered (Table 4). The time since the last dose was $>90$ days for most vaccinated close contacts. The VE declined 90 days after the second dose of Spikevax ( $85 \%$ to $67 \%$; $p_{\text {comparison }}=0.003$ ) and Comirnaty $\left(70 \%\right.$ to $63 \%$; $\left.p_{\text {comparison }}=0.035\right)$, but not
90 days after the first dose of Vaxzevria (40\% to $52 \%$; $\left.\mathrm{p}_{\text {comparison }}=0.746\right)($ Supplementary Table S3).

Several VE estimates seemed slightly lower against the Delta variant than against the Alpha variant; however, all products maintained a notable protective effect against both variants (Supplementary Table S4).

\section{Comparisons of product-specific full vaccination effectiveness}

Among people aged 18-59 years, product-specific VE within 90 days since the last dose was compared. Compared with vaccination with Janssen, the relative VE was 66\% (95\% Cl: 54 to 75) for Spikevax, 39\% (95\% Cl: 28 to 49) for Comirnaty and 69\% (95\% Cl: 34 to 86 ) for the Vaxzevria-Comirnaty combination. Similarly, full vaccination with Spikevax (66\%; 95\% Cl: 53 to 75 ), Comirnaty (38\%; 95\% Cl: 26 to 48 ) and the VaxzevriaComirnaty combination (69\%; $95 \% \mathrm{Cl}: 33$ to 85 ) were more effective than two doses of Vaxzevria.

\section{Ethical statement}

This study was approved by the Navarre's Ethical Committee for Clinical Research (PI2020/45), which waived the requirement of obtaining informed consent. 
TABLE 4

Product-specific COVID-19 vaccine effectiveness against SARS-CoV-2 infection by vaccination status of the index case and contact setting, dynamic cohort, Navarre, Spain, April-August $2021(\mathrm{n}=30,240)$

\begin{tabular}{|c|c|c|c|c|}
\hline $\begin{array}{l}\text { Study population and close contact vaccination } \\
\text { status }\end{array}$ & Cases/total & $\begin{array}{c}\text { Secondary attack rate, } \\
\%\end{array}$ & $\begin{array}{l}\text { Crude VE } \\
(95 \% \mathrm{Cl})\end{array}$ & $\begin{array}{c}\text { Adjusted } \\
\text { VE }(95 \% \mathrm{CI})^{\mathrm{a}}\end{array}$ \\
\hline \multicolumn{5}{|l|}{ Close contacts of unvaccinated index cases } \\
\hline Unvaccinated & $4,559 / 13,485$ & 34 & Reference & Reference \\
\hline 1 dose of Janssen & $151 / 779$ & 19 & $43(33$ to 51$)$ & $54(46$ to 62$)$ \\
\hline 1 dose of Spikevax & $55 / 393$ & 14 & 59 (46 to 68$)$ & $65(54$ to 73$)$ \\
\hline 2 doses of Spikevax & $55 / 850$ & 6 & $81(75$ to 85$)$ & $85(80$ to 88$)$ \\
\hline 1 dose of Comirnaty & $272 / 1,569$ & 17 & $49(42$ to 55$)$ & $57(51$ to 62$)$ \\
\hline 2 doses of Comirnaty & $716 / 5,606$ & 13 & $62(59$ to 65$)$ & $70(67$ to 73$)$ \\
\hline 1 dose of Vaxzevria & $246 / 1,277$ & 19 & $43(35$ to 50$)$ & $42(33$ to 49$)$ \\
\hline 2 doses of Vaxzevria & $176 / 982$ & 18 & $47(38$ to 54$)$ & $55(47$ to 62$)$ \\
\hline 1 dose of Vaxzevria +1 dose of Comirnaty & $7 / 83$ & 8 & 75 (48 to 88$)$ & $80(59$ to 91$)$ \\
\hline \multicolumn{5}{|l|}{ Close contacts of fully-vaccinated index cases } \\
\hline Unvaccinated & $118 / 394$ & 30 & Reference & Reference \\
\hline 1 dose of Janssen & $47 / 167$ & 28 & $6(-32$ to 33$)$ & $23(-14$ to 48$)$ \\
\hline 1 dose of Spikevax & $8 / 77$ & 10 & $65(29$ to 83$)$ & $64(26$ to 83$)$ \\
\hline 2 doses of Spikevax & $24 / 220$ & 11 & $64(43$ to 76$)$ & $70(52$ to 81$)$ \\
\hline 1 dose of Comirnaty & $38 / 216$ & 18 & 41 (15 to 59$)$ & $43(18$ to 61$)$ \\
\hline 2 doses of Comirnaty & $286 / 1,839$ & 16 & $48(36$ to 58$)$ & $59(45$ to 69$)$ \\
\hline 1 dose of Vaxzevria & $18 / 124$ & 15 & $51(20$ to 70$)$ & $43(2$ to 67$)$ \\
\hline 2 doses of Vaxzevria & $73 / 420$ & 17 & $42(22$ to 57$)$ & $41(16$ to 58$)$ \\
\hline 1 dose of Vaxzevria +1 dose of Comirnaty & $0 / 30$ & NA & NA & NA \\
\hline \multicolumn{5}{|l|}{ Household close contacts } \\
\hline Unvaccinated & $2,869 / 6,494$ & 44 & Reference & Reference \\
\hline 1 dose of Janssen & $179 / 741$ & 24 & $45(36$ to 53$)$ & $42(32$ to 51$)$ \\
\hline 1 dose of Spikevax & $42 / 254$ & 17 & $63(49$ to 72$)$ & $62(49$ to 72$)$ \\
\hline 2 doses of Spikevax & $68 / 769$ & 9 & 80 (74 to 84$)$ & $79(73$ to 84$)$ \\
\hline 1 dose of Comirnaty & $248 / 1,152$ & 22 & $51(44$ to 57$)$ & $51(44$ to 58$)$ \\
\hline 2 doses of Comirnaty & $811 / 5,048$ & 16 & $64(61$ to 66$)$ & $65(62$ to 69$)$ \\
\hline 1 dose of Vaxzevria & $232 / 913$ & 25 & $42(34$ to 50$)$ & $35(25$ to 43$)$ \\
\hline 2 doses of Vaxzevria & $185 / 863$ & 21 & 51 (44 to 58$)$ & $50(41$ to 58$)$ \\
\hline 1 dose of Vaxzevria +1 dose of Comirnaty & $5 / 71$ & 7 & $84(62$ to 93$)$ & $84(61$ to 93$)$ \\
\hline \multicolumn{5}{|l|}{ Non-household close contacts } \\
\hline Unvaccinated & $1,942 / 7,854$ & 25 & Reference & Reference \\
\hline 1 dose of Janssen & $30 / 256$ & 12 & $53(32$ to 67$)$ & $54(33$ to 68$)$ \\
\hline 1 dose of Spikevax & $28 / 263$ & 11 & $57(37$ to 70$)$ & 66 (50 to 76$)$ \\
\hline 2 doses of Spikevax & $17 / 358$ & 5 & $81(69$ to 88$)$ & $83(72$ to 90$)$ \\
\hline 1 dose of Comirnaty & $103 / 870$ & 12 & $52(42$ to 61$)$ & $56(46$ to 64$)$ \\
\hline 2 doses of Comirnaty & $259 / 2,924$ & 9 & $64(59$ to 68$)$ & $68(62$ to 73$)$ \\
\hline 1 dose of Vaxzevria & $70 / 686$ & 10 & $59(48$ to 67$)$ & $45(29$ to 57$)$ \\
\hline 2 doses of Vaxzevria & $87 / 676$ & 13 & $48(35$ to 58$)$ & $54(42$ to 63$)$ \\
\hline 1 dose of Vaxzevria +1 dose of Comirnaty & $2 / 48$ & 4 & $83(33$ to 96$)$ & 86 (43 to 96$)$ \\
\hline
\end{tabular}

$\mathrm{CI}$ : confidence interval; COVID-19: coronavirus disease; NA: not applicable; SARS-CoV-2: severe acute respiratory syndrome coronavirus 2; VE: vaccine effectiveness.

a $V E$ adjusted by age group (18-34, 35-49, 50-69 and $\geq 70$ years), sex, major chronic conditions, contact setting (household or other), month and vaccination status of index case.

These analyses estimate the vaccine effectiveness by product, but product comparison may not be valid. 


\section{Discussion}

The results show a clear effectiveness of the full COVID-19 vaccination with each of the four evaluated vaccine products and highlight some improvement points. Our findings are consistent with previous studies that reported high effectiveness of full COVID-19 vaccination in preventing hospitalisations [9-11] and moderate VE in preventing symptomatic and asymptomatic SARS-CoV-2 infection $[12,13]$. However, few studies evaluated VE for specific products $[11,14]$.

Two doses of mRNA vaccine or the heterologous vector/mRNA vaccination provided high protection against infection in the population 60 years of age. However, a decrease in the VE was observed from 90 days after the last dose that raises doubts about the duration of this effect.

The COVID-19 VE for the same product was lower in the elderly people. Therefore, full vaccination effect seemed suboptimal to prevent infection in this age group and to achieve transmission control in locations with a high proportion of older population as has been shown in other studies $[10,12]$. Younger age groups vaccinated with one dose of Janssen or two doses of Vaxzevria had also a suboptimal protection against SARS-CoV-2 infection [13].

Our results are consistent with the stronger immunological response observed in individuals who received the Vaxzevria-Comirnaty combination than those who received two doses of Vaxzevria $[15,16]$. This supports the recommendation of this heterologous vaccination in Spain and several other countries $[8,17]$.

Although the COVID-19 VE may be slightly lower against the Alpha and Delta variants, full vaccination remains notably protective against these variants of concern as also shown by Lopez Bernal et al. [18].

Regardless of the product, two-dose vaccination remained highly effective in preventing hospitalisation; however, the VE of one dose of Janssen seemed slightly lower. The suboptimal VE in preventing infection in fully vaccinated people, because of older age, vaccine type or time from the last dose, may be insufficient for infection control. A booster dose of vaccine in some cases has been suggested as a possible solution $[19,20]$.

The present study has advantages of the cohort design while all cases were laboratory-confirmed and non-cases were those who tested negative for SARSCoV-2 as in the test-negative design and the analysis of close contacts ensures similar exposure to infection $[12,13,21]$. However, this study also has some limitations. Vaccination coverage varied with age, comorbidity and month; nevertheless, analyses were adjusted for these variables. Since characteristics of people who received each vaccine product were different, specific estimates can be considered separately and care must be taken in comparisons. The correlation among close contacts of the same index case was not controlled for. Epidemiological and vaccination conditions of this study may not be similar to other sites. Estimates refer to the first 8 months since vaccination and VE may wane over time.

\section{Conclusions}

Regardless of the product, two vaccine doses were highly effective against hospitalisation, and mRNA or heterologous vaccination provided high protection within 90 days against SARS-CoV-2 infection in those younger than 60 years of age. However, protection against infection was suboptimal for vector-based vaccines in adults and for all products among people $\geq 60$ years old. Additional preventive measures should be maintained while SARS-CoV-2 is circulating to interrupt transmission in the population and product-specific VE should be monitored in the long term.

Investigators, other members of the Working Group for the Study of COVID-19 in Navarre

Carmen Martín, Isabel Polo, Amaya Bacaicoa, Judith Chamorro, Juana Vidán, Ingrid Estévez, Igberto Tordoya, Delia Quílez, Francisco Lameiro, Ana Isabel Álvaro, Esther Albéniz, Aitziber Echeverría, Paula López Moreno, Javier Gorricho, Eva Ardanaz, Maite Arriazu, Fernando Baigorria, Aurelio Barricarte, Enrique de la Cruz, Jorge Díaz, Nerea Egüés, Manuel García Cenoz, Nerea Iriarte, Kenya Nekotxea, Conchi Moreno-Iribas, Carmen Sayón, Maitane Tellechea, Marian Nuín.

\section{Acknowledgements}

Funding: This study was supported by the Horizon 2020 program of the European Commission (I-MOVE-COVID-19, grant agreement No 101003673) and by the Carlos III Institute of Health with the European Regional Development Fund (COV20/00542).

\section{Conflict of interest}

None declared.

Authors' contributions

IMB, IC and JC designed the study. CT-S, AM, MF-H, MEP, AN, and $C E$ were responsible for virological analyses. The members of the working group participated in the data collection. $I C, C B$ and $M G$ organized the epidemiological databases. IMB, MG and JC undertook the statistical analysis. IMB, MG and $J C$ wrote the draft manuscript, and all authors revised and approved the final version.

\section{References}

1. Polack FP, Thomas SJ, Kitchin N, Absalon J, Gurtman A, Lockhart S, et al. Safety and efficacy of the BNT162 b2 mRNA Covid-19 vaccine. N Engl J Med. 2020;383(27):2603-15. https:// doi.org/10.1056/NEJMoa2034577 PMID: 33301246

2. Voysey M, Costa Clemens SA, Madhi SA, Weckx LY, Folegatti PM, Aley PK, et al. Single-dose administration and the influence of the timing of the booster dose on immunogenicity and efficacy of ChAdOx1 nCoV-19 (AZD1222) vaccine: a pooled analysis of four randomised trials. Lancet. 
2021;397(10277):881-91. https://doi.org/10.1016/S01406736(21)00432-3 PMID: 33617777

3. Baden LR, El Sahly HM, Essink B, Kotloff K, Frey S, Novak R, et al. Efficacy and safety of the mRNA-1273 SARS-CoV-2 vaccine. N Engl J Med. 2021;384(5):403-16. https://doi.org/10.1056/ NEJMoa2035389 PMID: 33378609

4. Sadoff J, Gray G, Vandebosch A, Cárdenas V, Shukarev G, Grinsztejn B, et al. Safety and efficacy of singledose Ad26.COV2.S vaccine against Covid-19. N Engl J Med. 2021;384(23):2187-201. https://doi.org/10.1056/ NEJMoa2101544 PMID: 33882225

5. Ministerio de Sanidad. Estrategia de detección precoz, vigilancia y control de COVID-19. [Strategy for early detection, surveillance and COVID-19 control]. Madrid: Ministerio de Sanidad; 2021. Spanish. Available from: https://www.mscbs. gob.es/profesionales/saludPublica/ccayes/alertasActual/ nCov/documentos/COVID19_Estrategia_vigilancia_y_ control_e_indicadores.pdf

6. European Centre for Disease Prevention and Control (ECDC). Contact tracing: public health management of persons, including healthcare workers, who have had contact with COVID-19 cases in the European Union -third update, 18 November 2020. Stockholm: ECDC; 2020. Available from: https://www.ecdc.europa.eu/sites/default/files/documents/ covid-19-contact-tracing-public-health-management-thirdupdate.pdf

7. European Centre for Disease Prevention and Control (ECDC). Options for the use of rapid antigen tests for COVID-19 in the EU/EEA and the UK. 19 November 2020. Stockholm: ECDC; 2020. Available from: https://www.ecdc.europa.eu/sites/ default/files/documents/Options-use-of-rapid-antigen-testsfor-COVID-19_0.pdf

8. Consejo Interterritorial del Sistema Nacional de Salud. Estrategia de vacunación frente a COVID-19 en España. [Vaccination strategy against COVID-19 in Spain]. Madrid: Ministerio de Sanidad; 2021. Spanish. Available from: https://www.mscbs.gob.es/profesionales/saludPublica/ prevPromocion/vacunaciones/covid19/docs/COVID-19_ Actualizacion6_EstrategiaVacunacion.pdf

9. Haas EJ, Angulo FJ, McLaughlin JM, Anis E, Singer SR, Khan F, et al. Impact and effectiveness of mRNA BNT162 b2 vaccine against SARS-CoV-2 infections and COVID-19 cases, hospitalisations, and deaths following a nationwide vaccination campaign in Israel: an observational study using national surveillance data. Lancet. 2021;397(10287):181929. https://doi.org/10.1016/S0140-6736(21)00947-8 PMID: 33964222

10. Lopez Bernal J, Andrews N, Gower C, Robertson C, Stowe J, Tessier E, et al. Effectiveness of the Pfizer-BioNTech and Oxford-AstraZeneca vaccines on covid-19 related symptoms, hospital admissions, and mortality in older adults in England: test negative case-control study. BMJ. 2021;373(1088):n1088. https://doi.org/10.1136/bmj.n1088 PMID: 33985964

11. Thompson MG, Stenehjem E, Grannis S, Ball SW, Naleway AL, Ong TC, et al. Effectiveness of Covid-19 Vaccines in ambulatory and inpatient care settings. N Engl J Med. 2021;NEJMoa2110362. PMID: 34496194

12. Martínez-Baz I, Miqueleiz A, Casado I, Navascués A, Trobajo-Sanmartín C, Burgui C, et al. Effectiveness of COVID-19 vaccines in preventing SARS-CoV-2 infection and hospitalisation, Navarre, Spain, January to April 2021. Euro Surveill. 2021;26(21):2100438. https://doi.org/10.2807/156o7917.ES.2021.26.21.2100438 PMID: 34047271

13. de Gier B, Andeweg S, Joosten R, Ter Schegget R, Smorenburg $\mathrm{N}$, van de Kassteele J, et al. Vaccine effectiveness against SARS-CoV-2 transmission and infections among household and other close contacts of confirmed cases, the Netherlands, February to May 2021. Euro Surveill. 2021;26(31):2100640. https://doi.org/10.2807/1560-7917.ES.2021.26.31.2100640 PMID: 34355689

14. Self WH, Tenforde MW, Rhoads JP, Gaglani M, Ginde AA, Douin DJ, et al. Comparative effectiveness of Moderna, Pfizer-BioNTech, and Janssen (Johnson \& Johnson) vaccines in preventing COVID-19 hospitalizations among adults without immunocompromising conditions - United States, MarchAugust 2021. MMWR Morb Mortal Wkly Rep. 2021;70(38):133743. https://doi.org/10.15585/mmwr.mm7038e1 PMID: 34555004

15. Borobia AM, Carcas AJ, Pérez-Olmeda M, Castaño L, Bertran MJ, García-Pérez J, et al. Immunogenicity and reactogenicity of BNT162b2 booster in ChAdOx1-S-primed participants (CombiVacS): a multicentre, open-label, randomised, controlled, phase 2 trial. Lancet. 2021;398(10295):121-30. https://doi.org/10.1016/S0140-6736(21)01420-3 PMID: 34181880

16. Schmidt T, Klemis V, Schub D, Mihm J, Hielscher F, Marx S, et al. Immunogenicity and reactogenicity of heterologous ChAdOx1 nCoV-19/mRNA vaccination. Nat Med. 2021;27(9):1530-5. https://doi.org/10.1038/s41591-02101464-w PMID: 34312554

17. European Centre for Disease Prevention and Control (ECDC). Partial COVID-19 vaccination, vaccination following SARS$\mathrm{CoV}-2$ infection and heterologous vaccination schedule: summary of evidence. 22 July 2021. Stockholm: ECDC; 2021. Available from: https://www.ecdc.europa.eu/sites/default/ files/documents/Partial\%20COVID\%20vaccination $\% 20$ and $\% 20$ heterologous $\% 2$ ovacc $\% 2$ schedule $\% 20-\% 2022 \% 20 J u l y \% 20$ 2021.pdf

18. Lopez Bernal J, Andrews N, Gower C, Gallagher E, Simmons R, Thelwall S, et al. Effectiveness of Covid-19 vaccines against the B.1.617.2 (Delta) Variant. N Engl J Med. 2021;385(7):585-94. https://doi.org/10.1056/NEJMoa2108891 PMID: 34289274

19. Centers for Disease Control and Prevention (CDC). Joint Statement from HHS Public Health and Medical Experts on COVID-19 Booster Shots. Atlanta: CDC. 18 Aug 2021. Available from: https://www.cdc.gov/media/releases/2021/s0818-covid19-booster-shots.html

20. European Centre for Disease Prevention and Control (ECDC). Interim public health considerations for the provision of additional COVID-19 vaccine doses, 1 September 2021. Stockholm: ECDC; 2021. Available from: https://www.ecdc. europa.eu/sites/default/files/documents/Interim-publichealth-considerations-for-the-provision-of-additional-COVID19-vaccine-doses.pdf

21. Lewnard JA, Patel MM, Jewell NP, Verani JR, Kobayashi M, Tenforde MW, et al. Theoretical framework for retrospective studies of the effectiveness of SARS-CoV-2 vaccines. Epidemiology. 2021;32(4):508-17. https://doi.org/10.1097/ EDE.0000000000001366 PMID: 34001753

\section{License, supplementary material and copyright}

This is an open-access article distributed under the terms of the Creative Commons Attribution (CC BY 4.0) Licence. You may share and adapt the material, but must give appropriate credit to the source, provide a link to the licence and indicate if changes were made.

Any supplementary material referenced in the article can be found in the online version.

This article is copyright of the authors or their affiliated institutions, 2021. 